\title{
Monomer-Isomerization Polymerization XXXIV. Active Sites for Isomerization in Monomer-Isomerization Polymerization of 2-Butene with Ziegler-Natta Catalyst
}

\author{
Kiyoshi Endo, Ryuichi UedA, and Takayuki OTsu \\ Department of Applied Chemistry, Faculty of Engineering, \\ Osaka City University, Sugimoto, Sumiyoshi-ku, \\ Osaka 558, Japan
}

(Received February 12, 1991)

\begin{abstract}
Monomer-isomerization polymerization of cis-2-butene (c2B) with Ziegler-Natta catalysts was investigated to clarify the isomerization mechanism. With the $\mathrm{TiCl}_{3}-\left(\mathrm{C}_{2} \mathrm{H}_{5}\right)_{3} \mathrm{Al}$ catalyst, the isomerization of $\mathrm{c} 2 \mathrm{~B}$ to 1-butene $(1 \mathrm{~B})$ and trans-2-butene $(\mathrm{t} 2 \mathrm{~B})$ was determined as 42.7 and $52.8 \mathrm{~kJ} \mathrm{~mol}^{-1}$, respectively; i.e., the activation energy for geometric isomerization was higher than that for the positional one. From the effects of alkylaluminums on the monomer-isomerization polymerization of $\mathrm{C} 2 \mathrm{~B}$ and analysis of gaseous materials produced from the catalyst components, isomerization was concluded via a $\sigma$-alkylmetal complexes formed by the insertion of c2B into the $\mathrm{Ti}^{2+}-\mathrm{H}$ bond produced from the catalyst components.
\end{abstract}

KEY WORDS Monomer-Isomerization Polymerization / Ziegler-Natta Catalyst / 2-Butene / $\sigma$-Alkylmetal Complex / Activation Energy / Active Site for Isomerization /

We reported that monomer-isomerization polymerizations of internal olefins are induced with Ziegler-Natta catalysts according to eq 1, and are composed of two distinct reactions, i.e., isomerization and polymerization. ${ }^{1-11}$ Thus, this polymerization can be regarded as one-pot two stage reactions.

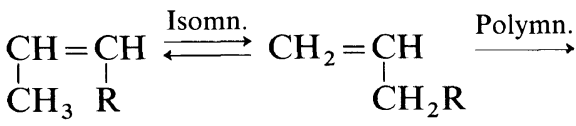

$$
\begin{aligned}
& \left(\begin{array}{r}
\mathrm{CH}_{2}-\mathrm{CH} \\
\quad \mathrm{CH}_{2} \mathrm{R}
\end{array}\right)_{n}
\end{aligned}
$$

Since both reactions take place at different active sites, ${ }^{4,5}$ the Ziegler-Natta catalysts used in this polymerization are required to have both active sites for isomerization and polymerization.

Moreover, isomerization should take place prior to polymerization and influence polymer yields. When the $\mathrm{TiCl}_{3}-\left(\mathrm{C}_{2} \mathrm{H}_{5}\right)_{3} \mathrm{Al}$ catalyst was used, the composition of unpolymerized butene recovered after the reactions gradually approached the equilibrium concentration after prolonged reactions. The addition of isomerization catalyst such as $\mathrm{NiCl}_{2}$ to $\mathrm{TiCl}_{3}$ $\left(\mathrm{C}_{2} \mathrm{H}_{5}\right)_{3} \mathrm{Al}$ enhanced the polymer yields as a result of acceleration of isomerization. ${ }^{3,6}$ Namely, isomerization plays a role in determining polymer yields, although, of course, the catalytic activity for polymerization is an important factor. Therefore, it is significant to elucidate the isomerization mechanism in order to find a high active catalyst for monomerisomerization polymerization.

For the isomerization of olefins with transition metal complexes, two different mechanisms have been proposed: one involves $\sigma$-alkylmetal complexes ${ }^{12-15}$ and the other $\pi$-allylmetal complexes. ${ }^{15-18}$ In the previous paper, ${ }^{4}$ we assumed that the isomerization of 
olefins with Ziegler-Natta catalysts proceeds via a $\sigma$-alkylmetal complexes.

In this paper, the monomer-isomerization of cis-2-butene (c2B) was studied, and the results are described.

\section{EXPERIMENTAL}

\section{Materials}

Commercial 1-butene (1B), c2B and trans2-butene ( $\mathrm{t} 2 \mathrm{~B})$ were used after fractional distillation over calcium hydride. The purities determined by gas chromatography were 99.8 , 99.7 and $99.0 \%$, respectively. Alkylaluminums and hydrogen-activated $\mathrm{TiCl}_{3}$ (commercial reagents) were used without further purification. Solvents and other reagents were used after purification by standard methods.

\section{Polymerization Procedure}

Polymerizations were carried out in a sealed glass tube. Charging of the required amounts of reagents into glass tubes and isolation of the polymers formed were carried out by methods described in a previous paper. ${ }^{2}$ The composition of the unpolymerized butenes recovered after polymerization was determined by gas chromatography using VZ-7 as column packing at $0^{\circ} \mathrm{C}$. The residue was then poured into a large amount of methanol containing a small amount of hydrochloric acid to precipitate the polymer, followed by filteration and drying. The polymer yield was calculated by gravimetry.

\section{RESULTS AND DISCUSSION}

\section{Activation Energy for Isomerization of $c 2 B$ with}

$\mathrm{TiCl}_{3}-\left(\mathrm{C}_{2} \mathrm{H}_{5}\right)_{3} \mathrm{Al}$ Catalyst

Monomer-isomerization polymerization of c2B was carried out with $\mathrm{TiCl}_{3}-\left(\mathrm{C}_{2} \mathrm{H}_{5}\right)_{3} \mathrm{Al}$ catalyst at temperatures from $50^{\circ} \mathrm{C}$ to $90^{\circ} \mathrm{C}$. Monomer-isomerization polymerization of c2B was induced at these temperatures. The results of the isomerization of $\mathrm{c} 2 \mathrm{~B}$ are shown in Figure 1. Positional and geometric isomerizations were found to take place simultaneously, and isomerization proceeded as a function of time.

Although it is difficult to separate isomerization from polymerization in the monomerisomerization polymerization, polymer yield is considered to be sufficient low as compared with the amount of $1 \mathrm{~B}$ produced by isomerization at the initial stage of the reaction, so that the initial rates of geometric and positional isomerizations were estimated.

The relations between the initial rates and
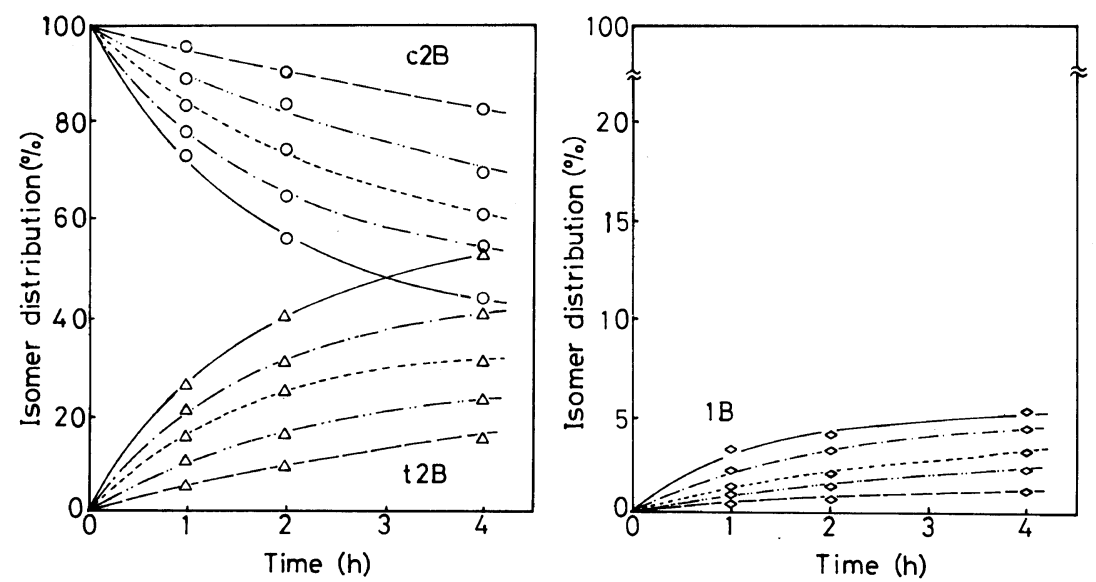

Figure 1. Isomerization of $\mathrm{c} 2 \mathrm{~B}$ with the $\mathrm{TiCl}_{3}-\left(\mathrm{C}_{2} \mathrm{H}_{5}\right)_{3} \mathrm{Al}$ catalyst. Polymerization conditions: $\left[\mathrm{TiCl}_{3}\right]=50 \mathrm{~m} \mathrm{moll}^{-1} ;[\mathrm{c} 2 \mathrm{~B}]=4.0 \mathrm{moll}^{-1} ; \mathrm{Al} / \mathrm{Ti}=3.0$ in molar ratio; $(\diamond) 1 \mathrm{~B} ;(\triangle) \mathrm{t} 2 \mathrm{~B} ;(\bigcirc) \mathrm{c} 2 \mathrm{~B} ;(\longrightarrow)$ $90^{\circ} \mathrm{C}$; (-. - ) $80^{\circ} \mathrm{C}$; (-----) $70^{\circ} \mathrm{C}$; (- - - $60^{\circ} \mathrm{C}$; (--) $50^{\circ} \mathrm{C}$. 
temperatures were plotted according to the Arrhenius equation, and the results are shown in Figure 2. From the slopes of the straight lines, the apparent activation energies for positional and geometric isomerizations were estimated to be 42.7 and $52.8 \mathrm{~kJ} \mathrm{~mol}^{-1}$, respectively. The results are summarized in Table I, in which the previous results of the isomerization of $\mathrm{t} 2 \mathrm{~B}$ are also shown. ${ }^{4}$ The activation energy for positional isomerization is $c a .10 \mathrm{~kJ} \mathrm{~mol}^{-1}$ lower than that for geometric isomerization regardless of $\mathrm{c} 2 \mathrm{~B}$ and $\mathrm{t} 2 \mathrm{~B}$ used as initial olefins.

According to the $\sigma$-alkylmetal complex mechanism, positional and geometric isomer-

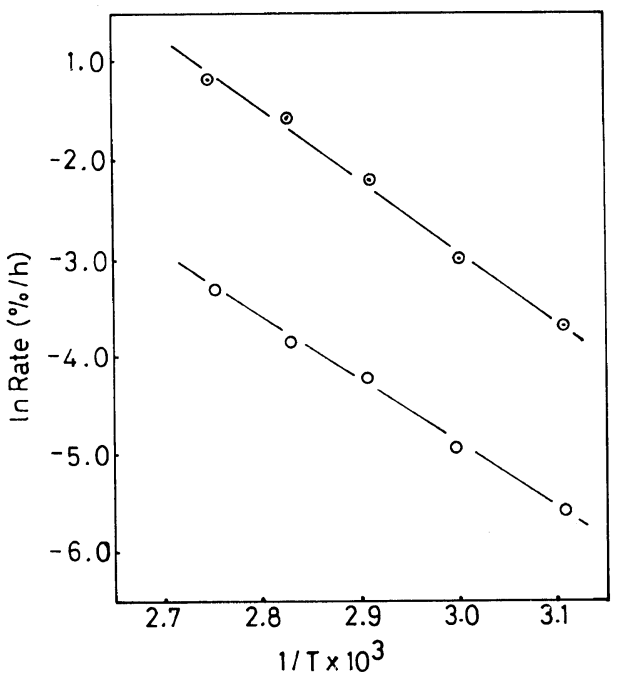

Figure 2. Arrhenius plots for the isomerization of $\mathrm{c} 2 \mathrm{~B}$ : (O), positional isomerization from $\mathrm{c} 2 \mathrm{~B}$ to $1 \mathrm{~B}$; $(\odot)$, geometric isomerization from $\mathrm{c} 2 \mathrm{~B}$ to $\mathrm{t} 2 \mathrm{~B}$. izations can be expressed by Scheme 1. To induce geometric isomerization by this mechanism, additional activation energy for the rotation of $\mathrm{C}-\mathrm{C}$ bond is required as compared with the positional isomerization. It is known that the activation energy for the rotation of $\mathrm{C}-\mathrm{C}$ bond is about $12 \mathrm{~kJ} \mathrm{~mol}^{-1},{ }^{19}$ so that the difference in activation energies between positional and geometric isomerization is likely to be attributed to the rotation energy of the $\mathrm{C}-\mathrm{C}$ bond in the complexes. Accordingly, the results are consistent with our previously assertion that isomerizations proceed via $\sigma$-alkylmetal complexes. ${ }^{4}$

\section{Hydride Source for Formation of $\mathrm{Ti}-\mathrm{H}$ Bond}

If the isomerization of olefins with $\mathrm{TiCl}_{3}$ $\left(\mathrm{C}_{2} \mathrm{H}_{5}\right)_{3} \mathrm{Al}$ proceeds by the $\sigma$-alkylmetal complex mechanism, the $\mathrm{Ti}-\mathrm{H}$ bond is required at the initial stage of the isomerization. For the formation of the $\mathrm{Ti}-\mathrm{H}$ bond, three possible routes may be considered as follows:

Table I. Activation energy of the isomerization of butene with the $\mathrm{TiCl}_{3}-\left(\mathrm{C}_{2} \mathrm{H}_{5}\right)_{3} \mathrm{Al}$ catalyst

\begin{tabular}{crlc}
\hline \multicolumn{2}{c}{$\begin{array}{c}\text { Butene } \\
\text { monomer }\end{array}$} & $\begin{array}{c}\text { Type of } \\
\text { isomerization }\end{array}$ & $\begin{array}{c}\text { Activation } \\
\text { energy }\end{array}$ \\
\cline { 4 - 4 } Reactant & Product & & $\mathrm{kJ} \mathrm{mol}^{-1}$ \\
\hline c2B & 1B & Positional & 42.7 \\
c2B & t2B & Geometric & 52.8 \\
t2B & 1B & Positional & 58.7 \\
t2B & c2B & Geometric & 67.0 \\
\hline
\end{tabular}

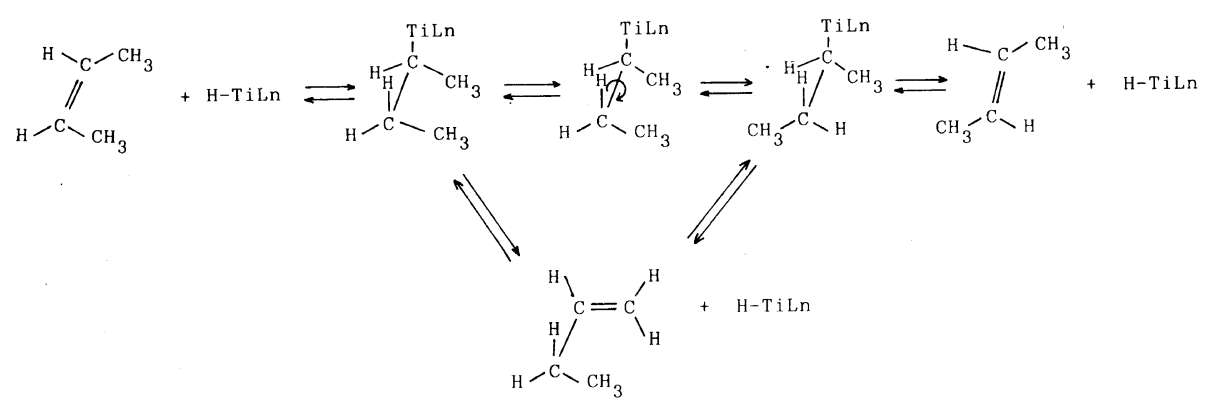

Scheme 1. Geometric and positional isomerization of butenes via the $\sigma$-alkyltitanium complex, Ln stands for ligand. 
A. Direct hydride-exchange reaction between titanium compounds and diethylaluminum hydride contained as a small amount of impurity $(\max .0 .5 \%)$ in triethylaluminum.

$$
\begin{gathered}
\mathrm{TiCl}_{n}+\left(\mathrm{C}_{2} \mathrm{H}_{5}\right)_{2} \mathrm{AlH} \longrightarrow \mathrm{HTiCl}_{n-1} \\
+\left(\mathrm{C}_{2} \mathrm{H}_{5}\right)_{2} \mathrm{AlCl}
\end{gathered}
$$

B. Decomposition by $\beta$-hydrogen elimination of the $\sigma$-alkyltitanium complex obtained from an alkyl-exchange reaction of titanium compounds and triethylaluminum. ${ }^{20}$

$$
\begin{aligned}
&\left(\mathrm{C}_{2} \mathrm{H}_{5}\right)_{3} \mathrm{Al}++\mathrm{TiCl}_{n} \longrightarrow \mathrm{C}_{2} \mathrm{H}_{5} \mathrm{TiCl}_{n-1} \\
&+\left(\mathrm{C}_{2} \mathrm{H}_{5}\right)_{2} \mathrm{AlCl} \\
& \mathrm{C}_{2} \mathrm{H}_{5} \mathrm{TiCl}_{n-1} \longrightarrow \mathrm{HTiCl}_{n-1}+\mathrm{C}_{2} \mathrm{H}_{4}
\end{aligned}
$$

C. Termination reaction by $\beta$-hydrogen elimination $^{21}$

$$
\begin{gathered}
\sim \mathrm{CH}_{2}-\mathrm{CH}_{2}-\mathrm{TiL}_{n} \longrightarrow \mathrm{HTiL}_{n}+ \\
\sim \mathrm{HC}=\mathrm{CH}_{2}
\end{gathered}
$$

To clarify this point, the monomer-isomerization polymerization of $\mathrm{c} 2 \mathrm{~B}$ was carried out with the $\mathrm{TiCl}_{3}-\left(\mathrm{C}_{2} \mathrm{H}_{5}\right)_{3} \mathrm{Al}$ catalyst. In the monomer-isomerization polymerization, the addition of isomerization catalysts to $\mathrm{TiCl}_{3}$ alkylaluminum enhanced polymer yields. ${ }^{3,6}$ This indicates that polymer yields should increase with the isomerization rate.

If the $\mathrm{Ti}-\mathrm{H}$ bond results from direct hydride-exchange reaction (eq 1), the polymerization of $\mathrm{c} 2 \mathrm{~B}$ with $\mathrm{TiCl}_{3}-\left(\mathrm{C}_{2} \mathrm{H}_{5}\right)_{2} \mathrm{AlH}$ catalyst should be faster than with other catalysts. As shown in Table II, however, such effects were not observed, and the composition of unpolymerized butenes recovered after the reactions was not different from the $\mathrm{TiCl}_{3}$ $\left(\mathrm{C}_{2} \mathrm{H}_{5}\right)_{3} \mathrm{Al}$ and $\mathrm{TiCl}_{3}$-(iso- $\left.\mathrm{C}_{4} \mathrm{H}_{9}\right)_{3} \mathrm{Al}$ catalysts. Thus, route $\mathrm{A}$ may not be the main route to produce the $\mathrm{Ti}-\mathrm{H}$ bond.

If termination reactions accompanying $\beta$ hydrogen elimination are the main route for the formation of $\mathrm{Ti}-\mathrm{H}$ bonds, the rate of the

\begin{tabular}{|c|c|c|c|c|}
\hline \multirow{3}{*}{ Alkylaluminum } & \multirow{3}{*}{$\begin{array}{c}\text { Yield } \\
\%\end{array}$} & \multicolumn{3}{|c|}{$\begin{array}{l}\text { Composition of } \\
\text { unpolymerized butenes } \\
\text { after polymerization }\end{array}$} \\
\hline & & \multicolumn{3}{|c|}{$\%^{\mathrm{b}}$} \\
\hline & & $1 \mathrm{~B}$ & $\mathrm{t} 2 \mathrm{~B}$ & $\mathrm{c} 2 \mathrm{~B}$ \\
\hline$\left(\text { iso- } \mathrm{C}_{4} \mathrm{H}_{9}\right)_{3} \mathrm{Al}$ & 17.6 & 2.3 & 65.1 & 35.6 \\
\hline$\left(\mathrm{C}_{2} \mathrm{H}_{5}\right)_{3} \mathrm{Al}$ & 12.7 & 2.3 & 53.6 & 44.1 \\
\hline$\left(\mathrm{C}_{2} \mathrm{H}_{5}\right)_{2} \mathrm{AlH}$ & 12.5 & 3.1 & 64.8 & 32.1 \\
\hline$\left(\mathrm{CH}_{3}\right)_{3} \mathrm{Al}$ & 0.0 & 0.1 & 3.2 & 96.7 \\
\hline
\end{tabular}
monomer-isomerization polymerization of $\mathrm{c} 2 \mathrm{~B}$ is enhanced by the presence of a small amount of $1 \mathrm{~B}$. Then, polymerization was carried out
Table II. Monomer-isomerization polymerization of $\mathrm{c} 2 \mathrm{~B}$ with the $\mathrm{TiCl}_{3}$-alkylaluminum catalyst in $n$-heptane at $80^{\circ} \mathrm{C}$ for $7.0 \mathrm{~h}^{\mathrm{a}}$

a Polymerization conditions $\left[\mathrm{TiCl}_{3}\right]=50 \mathrm{~m} \mathrm{moll}^{-1}$;

\begin{tabular}{|c|c|c|c|c|}
\hline \multirow{3}{*}{ Alkylaluminum - } & \multirow{3}{*}{$\begin{array}{c}\text { Yield } \\
\%\end{array}$} & \multicolumn{3}{|c|}{$\begin{array}{l}\text { Composition of } \\
\text { unpolymerized butenes } \\
\text { after polymerization }\end{array}$} \\
\hline & & \multicolumn{3}{|c|}{$\%^{\mathrm{b}}$} \\
\hline & & $1 \mathrm{~B}$ & $\mathrm{t} 2 \mathrm{~B}$ & $\mathrm{c} 2 \mathrm{~B}$ \\
\hline$\left(\text { iso- } \mathrm{C}_{4} \mathrm{H}_{9}\right)_{3} \mathrm{Al}$ & 22.4 & 2.0 & 64.3 & 33.7 \\
\hline$\left(\mathrm{C}_{2} \mathrm{H}_{5}\right)_{3} \mathrm{Al}$ & 17.3 & 0.9 & 47.0 & 52.1 \\
\hline$\left(\mathrm{C}_{2} \mathrm{H}_{5}\right)_{2} \mathrm{AlH}$ & 14.1 & 3.4 & 59.4 & 37.2 \\
\hline \multirow[t]{2}{*}{$\left(\mathrm{CH}_{3}\right)_{3} \mathrm{Al}$} & 1.9 & 0.9 & 4.3 & 94.8 \\
\hline & & $(3.0$ & 1.2 & $95.8)^{\mathrm{c}}$ \\
\hline
\end{tabular}
$[\mathrm{c} 2 \mathrm{~B}]=4.0 \mathrm{moll}^{-1} ; \mathrm{Al} / \mathrm{Ti}=3.0$ in molar ratio.

b Determined by gas chromatography.

Table III. Monomer-isomerization polymerization of $\mathrm{c} 2 \mathrm{~B}$ in the presence of $1 \mathrm{~B}$ with the $\mathrm{TiCl}_{3}$ alkylaluminum catalyst in $n$-heptane at $80^{\circ} \mathrm{C}$ for $7.0 \mathrm{~h}^{\mathrm{a}}$

a Polymerization conditions: $\left[\mathrm{TiCl}_{3}\right]=50 \mathrm{~m} \mathrm{moll}^{-1}$; $[\mathrm{c} 2 \mathrm{~B}]=4.0 \mathrm{moll}^{-1} ; \mathrm{Al} / \mathrm{Ti}=3.0$ in molar ratio.

b Determined by gas chromatography.

c Composition of initial butenes.

with $\mathrm{TiCl}_{3}$-alkylaluminum catalysts in the presence of $1 \mathrm{~B}$, and the results are shown in Table III. However, remarkable enhancement of polymer yields was not observed, suggesting that route $\mathrm{C}$ is not the main source of $\mathrm{Ti}-\mathrm{H}$ bonds.

$1 \mathrm{~B}$ can be polymerized readily with all the catalysts used as shown in Table IV. With $\mathrm{TiCl}_{3}-\left(\mathrm{CH}_{3}\right)_{3} \mathrm{Al}$ catalyst, however, neither 
Table IV. Polymerization of $1 \mathrm{~B}$ with the $\mathrm{TiCl}_{3}$ alkylaluminum catalyst in $n$-neptane at $80^{\circ} \mathrm{C}$ for $0.5 \mathrm{~h}^{\mathrm{a}}$

\begin{tabular}{|c|c|c|c|c|}
\hline \multirow{3}{*}{ Alkylaluminum } & \multirow{3}{*}{$\frac{\text { Yield }}{\%}$} & \multicolumn{3}{|c|}{$\begin{array}{l}\text { Composition of } \\
\text { unpolymerized butenes } \\
\text { after polymerization }\end{array}$} \\
\hline & & \multicolumn{3}{|c|}{$\%^{\mathrm{b}}$} \\
\hline & & $1 \mathrm{~B}$ & $\mathrm{t} 2 \mathrm{~B}$ & $\mathrm{c} 2 \mathrm{~B}$ \\
\hline (iso- $\left.\mathrm{C}_{4} \mathrm{H}_{9}\right)_{3} \mathrm{Al}$ & 99.4 & - & - & - \\
\hline$\left(\mathrm{C}_{2} \mathrm{H}_{5}\right)_{3} \mathrm{Al}^{\mathrm{c}}$ & 90.9 & 14.9 & 59.6 & 25.5 \\
\hline$\left(\mathrm{C}_{2} \mathrm{H}_{5}\right)_{2} \mathrm{AlH}$ & 77.1 & 73.9 & 12.4 & 13.7 \\
\hline$\left(\mathrm{CH}_{3}\right)_{3} \mathrm{Al}$ & 77.9 & 99.7 & 0.2 & 0.1 \\
\hline 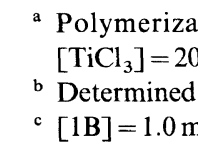 & $\begin{array}{l}\text { ion } \mathrm{c} \\
\text { m moll } \\
\text { by gas } \\
\end{array}$ & $\begin{array}{l}\mathrm{Al} / \mathrm{Ti} \\
\text { mato }\end{array}$ & $\begin{array}{l}1 \mathrm{~B}]= \\
\text { in mo } \\
\text { ly. }\end{array}$ & $\begin{array}{l}\text { moll } \\
\text { ratio. }\end{array}$ \\
\hline
\end{tabular}

isomerization nor monomer-isomerization polymerization took place (see Table III). Since $\left(\mathrm{CH}_{3}\right)_{3} \mathrm{Al}$ has no $\beta$-hydrogen, the isomerization site may be not formed.

On the basis of these results, intramolecular $\beta$-hydrogen elimination (route B) seems to be the main route for producing the isomerization site involving $\mathrm{Ti}-\mathrm{H}$ bonds.

Formation of $\mathrm{Ti}-\mathrm{H}$ bonds may be confirmed by analysis of product materials produced by reactions between the catalyst components. It is known that the bimolecular reductive elimination of an alkylmetal ( $\mathrm{RMt}^{n} \mathrm{Ln}: \mathrm{R}=\mathrm{alkyl}$, $\mathrm{L} n=$ ligand) gives equal amounts of the corresponding alkanes and alkenes (eq 6). Even when a coupling product (eq 7) is obtained based on the alkyl fragment, the ratios of alkane to alkene should not change. ${ }^{22}$ On the other hand, the $\beta$-hydrogen elimination of the alkylmetal produces only the corresponding alkenes (eq 4). ${ }^{20}$

$$
\begin{aligned}
2 \mathrm{RMt}^{n} \mathrm{Ln} \longrightarrow 2 \mathrm{Mt}^{n-1} \mathrm{Ln} & +\mathrm{R}(-\mathrm{H}) \\
& +\mathrm{R}(+\mathrm{H}) \\
2 \mathrm{RMt}^{n} \mathrm{Ln} \longrightarrow 2 \mathrm{Mt}^{n-1} \mathrm{Ln} & +\mathrm{R}-\mathrm{R}
\end{aligned}
$$

From analysis of the products obtained from reaction of $\mathrm{TiCl}_{3}$ with (iso- $\left.\mathrm{C}_{4} \mathrm{H}_{9}\right)_{3} \mathrm{Al}$, the amount of isobutene was higher than that of isobutane. This indicates that $\beta$-hydrogen elimination takes place along with the reduction of titanium compounds.

Moreover, the $\mathrm{TiCl}_{3}-\left(\mathrm{C}_{2} \mathrm{H}_{5}\right)_{2} \mathrm{AlCl}$ catalyst produced ethylene, but a significant amount of ethane was not observed in the reaction products, suggesting that the $\mathrm{Ti}^{3+}-\mathrm{H}$ bond is produced. However, this catalyst did not induce the isomerization of olefins. ${ }^{11}$ Hence, it is clear that the active sites for isomerization involve $\mathrm{Ti}^{2+}-\mathrm{H}$ bonds produced by the intramolecular $\beta$-hydrogen elimination of $\sigma$-alkyltitanium complexes, and polymerization sites are different from isomerization sites.

As for the oxidation state of titanium, three independent research groups have proved that $\mathrm{Ti}^{3+}$ containing complexes are active sites for 1-olefins polymerization, but $\mathrm{Ti}^{2+}$ containing complexes are inactive. ${ }^{23-25}$ Our results are consistent with these findings.

\section{REFERENCES}

1. A. Shimizu, T. Otsu, and M. Imoto, J. Polym. Sci., $B, 3,449,1031$ (1965).

2. T. Otsu, A. Shimizu, and M. Imoto, J. Polym. Sci., A-1, 4, 1579 (1966).

3. T. Otsu, A. Shimizu, and M. Imoto, J. Polym. Sci., A-1, 7, 3111 (1969).

4. T. Otsu, A. Shimizu, and M. Imoto, J. Polym. Sci., $A-1,7,3119$ (1969).

5. J. P. Kennedy and T. Otsu, Adv. Polym. Sci., 7, 369 (1970).

6. T. Otsu and K. Endo, J. Macromol. Sci-Chem., A9, 899,1249 (1975).

7. T. Otsu, K. Endo, H. Nagahama, and A. Shimizu, Bull. Chem. Soc. Jpn., 48, 2470 (1975).

8. K. Endo and T. Otsu, J. Polym. Sci., Polym. Chem. Ed., 14, 1889, 2083 (1976).

9. K. Endo, H. Nagahama, and T. Otsu, J. Polym. Sci., Polym. Chem. Ed., 17, 3647 (1979).

10. K. Endo and T. Otsu, J. Polym. Sci., Polym. Chem. Ed., 24, 1615 (1986).

11. K. Endo, H. Tsujikawa, and T. Otsu, J. Polym. Sci., Polym. Chem. Ed., 24, 1633 (1986).

12. T. A. Manuel, J. Org. Chem., 27, 3941 (1962).

13. G. L. Karapinka and M. Orchin, J. Org. Chem., 26, 4187 (1961).

14. R. Cramer and R. V. Lindsey, J. Am. Chem. Soc., 88, 3534 (1966). 


\section{K. Endo, R. Ueda, and T. Otsu}

15. G. Henrici-Olive and S. Olive, "Coordination and Catalysis," Verlag Chemie, Weinheim, 1977, p 156.

16. R. E. Reinhart and R. W. Fuest, Chem. Eng. News 43(7), 40 (1965).

17. H. Bonnemann, Angew. Chem. Internal. Ed., 9, 736 (1970).

18. C. P. Casey and C. R. Cyr, J. Am. Chem. Soc., 95, 2248 (1973).

19. F. A. Bovey and T. K. Kwei, "Macromolecules-An Introduction to Polymer Science," F. A. Bovey and F. H. Winslow, Ed., Academic Press, New York, N.Y., 1979, p 246.

20. J. Boor, Jr., "Ziegler-Natta Catalysts and Polymerizations," Academic Press, New York, N.Y.,
1979, p 110.

21. G. Natta, J. Polym. Sci., 34, 21 (1959).

22. L. Reich and A. Schindler, "Polymerization by Organometallic Compounds," Wiley, New York, N.Y., 1965, Chapters III and IV.

23. K. Soga, T. Sano, and R. Ohnishi, Polym. Bull., 4, 157 (1981).

24. N. Kashiwa and J. Yoshitake, Makromol. Chem., 114, 77 (1983).

25. S. Weber, J. C. W. Chien, and Y. Hu, "Transition Metals and Organometallics as Catalysts for Olefin Polymerization," W. Kaminsky and H. Sinn, Ed., Springer-Verlag, Berlin, Heidelberg, 1988, p 45. 